\title{
Device Contamination with Body Fluid
}

National Cancer Institute

\section{Source}

National Cancer Institute. Device Contamination with Body Fluid. NCI Thesaurus. Code C63016.

Problem associated with the undesired presence of body fluid in/on the device, which are not part of the documented device specifications and requirements. 